\title{
Automatic Detection System Satellite Orbit Position with a Method of Control Azimuth and Elevation Angles Parabolic Antenna
}

\author{
Budi Herdiana ${ }^{1}$, Deddy Gunawan ${ }^{2 *}$ \\ 1, 2 Department of Electrical Engineering, Universitas Komputer Indonesia, Bandung, Indonesia \\ Email: budi.herdiana@email.unikom.ac.id, scholarfun77@gmail.com \\ *Corresponding Author
}

\begin{abstract}
The automatic system satellite signal strength tracking model through the positioning of the receiving antenna is one way to reduce the problem of attenuation and signal strength instability which is quite influential in tracking the satellite orbit position. The method of applying the antenna movement technique by adjusting the azimuth and elevation angles is possible to detect the position of the satellite orbit trajectory accurately. Therefore, the expected goal is to know the existence of the satellite's orbital trajectory and ensure that the signal strength it transmits will always be stable in all conditions. The empirical quantitative method is used to support the achievement of these objectives where the technique is carried out through field observations and device design involving calculations and applied mathematical equations based on information on satellite position data as a tracking object as well as a source of signal strength. Based on the test results, it shows that all the positions of the tracked satellite orbital trajectories produce a minimum and maximum azimuth-elevation angle of $0.52 \%-4.02 \%$ and $0.25 \%-3.99 \%$ when the system detects NSS6. Furthermore, when the system detects Palapa $D$, the minimum values for the percentage of maximum deviation error are $0.6 \%$ and $4.67 \%$ with a tolerance of the alignment angle to the satellite of $<20$. Overall, the designed system is able to track the position of the satellite's orbit path based on the level of signal strength stability on the parabolic receiver antenna which is designed with small percentage of angle error.
\end{abstract}

Keywords - satellite, antenna parabolic, strength signal, azimuth, elevation, orbit

\section{INTRODUCTION}

Development of a tracking system for antenna signal strength in satellite communication are increasing and needed in determining the target position of the orbital trajectory of a satellite. The positioning of the satellite path requires increasing the gain of the receiving antenna although this will reduce the width of the antenna beam itself. Therefore, this tracking system is needed to control the movement of the angular position of the receiving antenna automatically. To improve its accuracy a design method is needed by taking one of the main parameters of the satellite orbital position namely the azimuth and elevation angles which are an important part of the designed system. Previous research describes a signal strength tracking system that only uses the azimuth angle parameter as the source of the tracking angle by only being applied indoors through Wi-Fi access points [1][2].
Other research results from advice the concept of tracking satellite signal amplification automatically through a closed loop algorithm approach which results in a miss position loss of $1 \mathrm{~dB}$ of the total tracking results [3]. While other research results explain the application of the auto-tracking design model using a microcontroller, GPS, sat finder, and digital compass to synchronize the azimuth and elevation angles to one satellite orbit position, namely the Cakrawarta-2 satellite, where this research also designed an automatic tracking device that points to the Cakrawarta satellite -2 which is in the corner of 107.35 East Longitude, the S-band frequency is $2520 \mathrm{MHz}-2670 \mathrm{MHz}$ [4][5]. The weakness of the previous signal strength tracking system has been improved by proposing the addition of a pointing control system that can produce accuracy and a minimum average error of $11.3^{\circ}$ (azimuth) and $1.2^{\circ}$ (elevation) even though the azimuth angle is still found to be deficient, namely fault tolerance is still under ITU-R regulatory standards of $2^{\circ}$ from its peak pointing [6].

Therefore, this research will design a development model of a signal strength automatic tracking device using a parabolic antenna type as a regulator to obtain variations in azimuth and elevation angles as input indicators to obtain signal strength at azimuth angles $\leq 2^{\circ}$ and elevation $\leq 2^{\circ}$ to minimize transmission losses. which affects the position of the orbital trajectory of the tracked satellite. Based on some information data obtained from previous research, the objective of this research is to develop a model of a satellite signal strong automation tracking system by a parabolic type earth receiver antenna which is used to determine the position of the orbit of the satellite trajectory accurately with a very high error detection value small.

\section{METHOD}

The method in this research used a quantitative empirical descriptive and field observation approach. Field observations were done by collecting information data such as the type of satellite to be tracked, the allocation of working frequency, and the signal strength condition of the last position of the satellite's orbit based on the value obtained from a standard signal strength measuring instrument. While the quantitative empirical descriptive method is used when the field information data has been previously obtained and then processed through calculations using a mathematical 
approach, then modeled into a system device. The system development model is shown through the research flow algorithm as illustrated in Fig. 1.

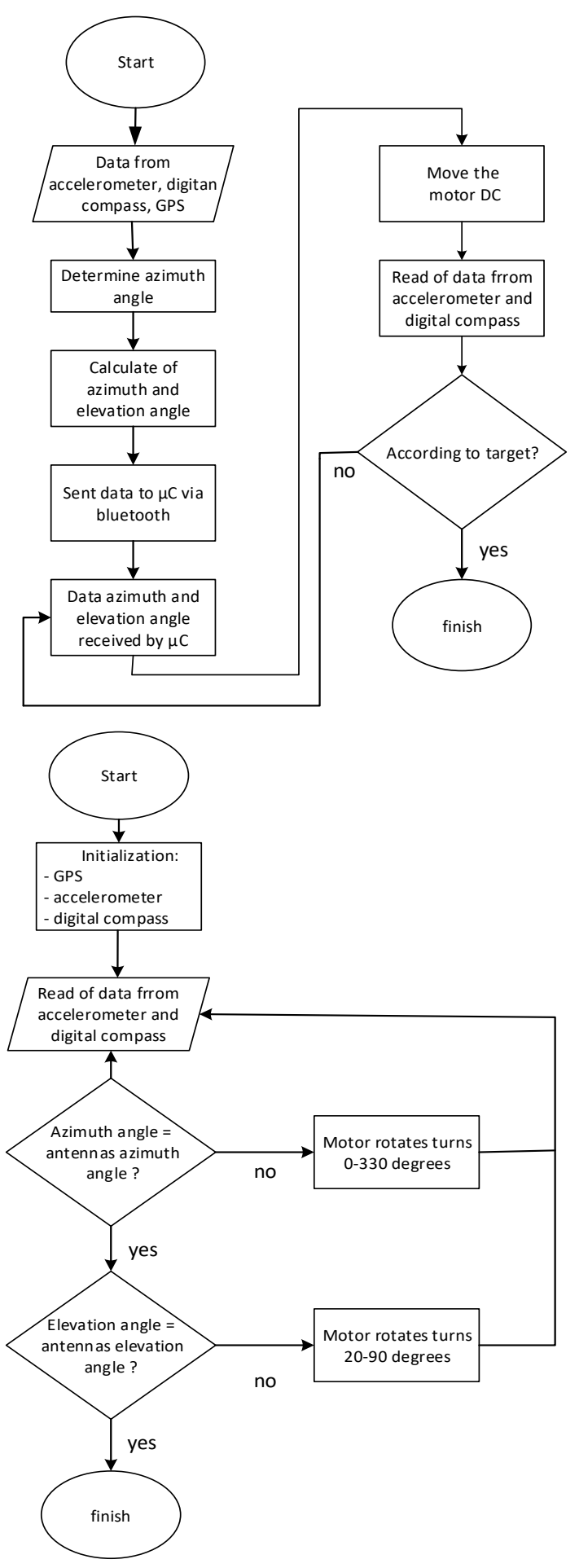

Fig. 1. Algorithm Design System

Linearly, changes in azimuth and elevation angles follow changes in signal strength received by the antenna, where the magnitude can be determined using equations (1) and (2).

$A^{\prime}=\tan ^{-1} \frac{[l s-l e]}{\sin L e}$
Where $A^{\prime}$ denotes the satellite azimuth angle. Changes in azimuth angle really depend on the position of latitude (Le), longitude of the receiving antenna (le) and satellite (ls). While the change in elevation angle is stated by the following equation:

$E=\tan ^{-1}\left[\frac{(6.6107345-\cos \gamma)}{\sin \gamma}\right]$

Where $E$ is the satellite elevation angle which will change its value linearly according with changes in the satellite azimuth angle.

\section{RESULT AND DISCUSSION}

The developed model requires testing so that the system is designed according to specifications to obtain good device performance. The test step is carried out using a comparison technique, which is to compare the results of the calculations with their measurements for several satellites, namely NSS6 and Palapa D.

\section{A. Block Diagram}

Based on the algorithm described in Fig. 1, it can be implemented into a system block as shown in Fig. 2.

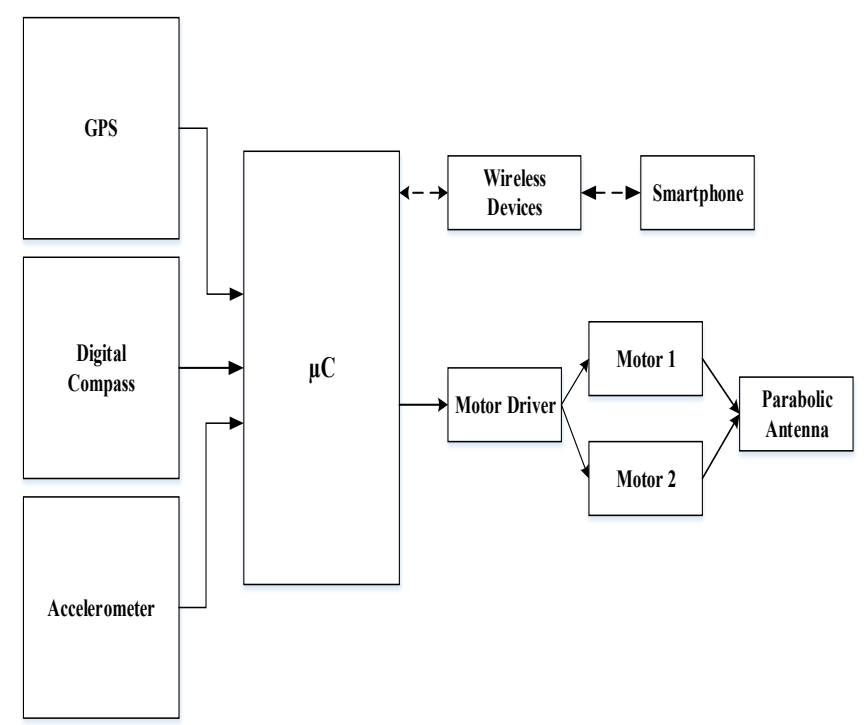

Fig. 2. Block Diagram of the System

The system is designed based on three parts, namely input, process, and output. The input section consists of several sensors such as GPS, digital compass, and accelerometer, which detect and track the orbital position of the satellite which provides information on the angle of the satellite position to the microcontroller. This microcontroller will translate the angular position of the sensor through the help of motor windows 1 and 2 to move the parabolic antenna to a certain signal strength point according to the position of the detected satellite orbit [7]-[12]. Smartphones receive notification information from the microcontroller which can set and monitor realtime with special specifications [13]-[16].

\section{B. Margin Error Value}

Test results show that the error margin value is a measure to determine the percentage accuracy of the final result based 
on the deviation parameter of the test result value with the reference value obtained from the calculation results for each satellite object as stated below:

- Azimuth angle of satellite NSS6

$$
\begin{aligned}
A^{\prime} & =\tan ^{-1} \frac{[\tan (1.658063-1.1878271)]}{\sin (-0.12017)} \\
& =61.82^{0}
\end{aligned}
$$

Azimuth $=360^{\circ}-61.82^{0}$

$$
=289.17^{0}
$$

- Elevation angle of satellite NSS6

$$
\begin{aligned}
\cos \gamma & =\cos (-0,12017) \cdot \cos (1.658063-1.1878271) \\
& =0.968815 \\
\gamma & =\cos ^{-1}(\cos \gamma) \\
& =\cos ^{-1}(0.968815) \\
& =0.250394 \\
\mathrm{E} & =\tan ^{-1}\left[\frac{(5.64192)}{(0.247786)}\right]-0.250394 \\
& =73.14^{0}
\end{aligned}
$$

- Azimuth angle of satellite PAPALA D

$$
\begin{aligned}
\mathrm{A}^{\prime} & =\tan ^{-1} \frac{[\tan (1.972222-1.1878271)]}{\sin (-0.12017)} \\
& =-38.16^{0}
\end{aligned}
$$

- Elevation angle of satellite PAPALA D

$$
\begin{aligned}
\cos \gamma & =\cos -0.12017 . \cos (1.972222-1.1878271) \\
& =0.98841 \\
\gamma & =\cos ^{-1}(\cos \gamma) \\
& =\cos ^{-1}(0.98841) \\
& =0.152395 \\
\mathrm{E}= & \tan ^{-1}\left[\frac{(5.622324)}{(0.152395)}\right]-0.152395 \\
= & 79.72^{0}
\end{aligned}
$$

The result of this calculation is used as a reference value to determine the angle deviation error based on the difference between the test and the calculation. Tables 1 and 2 show the results of the comparison data along with the percentage error margin value for the overall test results of azimuth and elevation angles on NSS6 and Palapa D satellites [17]-[20].

TABLE I. COMParison ANALysis Result OF SAtellite Position Nss6

\begin{tabular}{|c|c|c|c|c|c|c|}
\hline \multirow{2}{*}{ No } & \multicolumn{6}{|c|}{ Monitoring Position } \\
\cline { 2 - 7 } & \multicolumn{2}{|c|}{ Calculate Result } & \multicolumn{2}{c|}{$\begin{array}{c}\text { Detection } \\
\text { Result }\end{array}$} & \multicolumn{2}{c|}{$\begin{array}{c}\text { Margin Error } \\
(\%)\end{array}$} \\
\cline { 2 - 7 } & & & & & & \\
\hline 1 & 298.17 & 73.14 & 294.52 & 74.95 & 1.89 & 1.81 \\
\hline 2 & 298.17 & 73.14 & 296.18 & 71.92 & 4.02 & 1.22 \\
\hline 3 & 298.17 & 73.14 & 297.88 & 72.89 & 2.26 & 0.25 \\
\hline 4 & 298.17 & 73.14 & 297.99 & 73.64 & 2.20 & 0.50 \\
\hline 5 & 298.17 & 73.14 & 295.80 & 72.51 & 1.97 & 0.63 \\
\hline 6 & 298.17 & 73.14 & 296.10 & 74.54 & 0.52 & 1.40 \\
\hline 7 & 298.17 & 73.14 & 299.49 & 75.44 & 2.36 & 2.30 \\
\hline 8 & 298.17 & 73.14 & 297.45 & 72.84 & 1.21 & 0.30 \\
\hline
\end{tabular}

\begin{tabular}{|c|c|c|c|c|c|c|}
\hline 9 & 298.17 & 73.14 & 298.27 & 72.18 & 3.01 & 0.96 \\
\hline 10 & 298.17 & 73.14 & 297.43 & 74.42 & 2.94 & 1.28 \\
\hline
\end{tabular}

TABLE II.

COMPARison ANALYSIS Result OF SATELLite POSITION PALAPA D

\begin{tabular}{|c|c|c|c|c|c|c|}
\hline \multirow{2}{*}{ No } & \multicolumn{6}{|c|}{ Monitoring Position } \\
\cline { 2 - 7 } & \multicolumn{2}{|c|}{ Calculate Result } & \multicolumn{2}{c|}{$\begin{array}{c}\text { Detection } \\
\text { Result }\end{array}$} & \multicolumn{2}{c|}{$\begin{array}{c}\text { Margin Error } \\
(\%)\end{array}$} \\
\cline { 2 - 7 } & & & & & & \\
\hline 1 & 38.17 & 79.72 & 39.58 & 77.97 & 1.41 & 1.75 \\
\hline 2 & 38.17 & 79.72 & 41.37 & 77.59 & 3.20 & 2.13 \\
\hline 3 & 38.17 & 79.72 & 40.56 & 80.54 & 2.39 & 0.82 \\
\hline 4 & 38.17 & 79.72 & 42.57 & 79.58 & 4.4 & 0.14 \\
\hline 5 & 38.17 & 79.72 & 40.82 & 81.92 & 2.65 & 2.20 \\
\hline 6 & 38.17 & 79.72 & 37.32 & 79.59 & 0.85 & 0.13 \\
\hline 7 & 38.17 & 79.72 & 35.26 & 80.96 & 2.91 & 1.24 \\
\hline 8 & 38.17 & 79.72 & 33.5 & 78.55 & 4.67 & 1.17 \\
\hline 9 & 38.17 & 79.72 & 41.00 & 79.70 & 2.83 & 0.02 \\
\hline 10 & 38.17 & 79.72 & 37.57 & 78.45 & 0.60 & 1.27 \\
\hline
\end{tabular}

From the data shown in Tables 1 and 2, the system performance can be described through its characteristic curve as illustrated in Fig. 3.
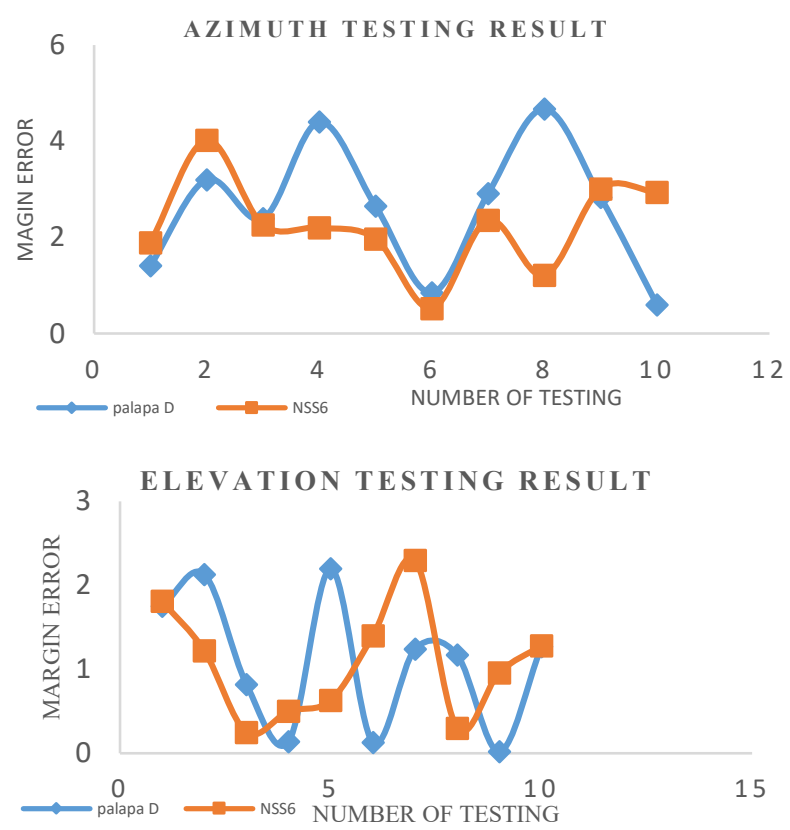

Fig. 3. Block Diagram of the System

The comparison of the azimuth and elevation angle test results shows that the change in the margin of error at the elevation angle is quite large compared to the azimuth angle which indirectly affects the change in signal gain received by the receiving antenna. Besides, the intensity of changes in the up and down of the signal strength occurs more due to the possibility of an obstacle in the transmission path so that the angle and level of the signal strength can easily change quickly [21]-[23].

The increase in changes in azimuth and elevation angles in the tracking position of the NSS 6 satellite was greater than that of Palapa D so that it had an impact on the quality of the resulting signal to be more varied. The results of this analysis 
are reinforced by the results of previous research which explain changes in the strength signal of satellite signals that will always result in a rapid change of azimuth angles and elevation values [24]-[27] while the accuracy is very much determined by the angle of movement of the tracking system with the position angle of the object being tracked [28]-[31].

\section{CONCLUSION}

Based on the results of the design and testing, it shows that the system can work well with an average margin of error below two degrees $(<20)$ by the research objectives, although some results are greater than two degrees. The successful performance of this system can be seen when this automation device can capture variations in changes in azimuth and elevation angles according to the surrounding environment with a minimum error percentage range of $0.52 \%$ and a maximum of $4.67 \%$.

\section{REFERENCES}

[1] J. Seitz, "Wi-Fi Azimuth and Position Tracking Using Directional Received Signal Strength Measurements", IEEE Workshop on Sensor Data Fusion: Trends, Solutions, Applications (SDF), 2012, p. $72-77$

[2] J. Seitz, and T. Vaupel, "Wi-Fi Azimuth and Position Tracking:Signal Propagation, Modeling and Evaluation", IEEE 16th International Conference on Information Fusion, 2013, p. $1479-1486$

[3] Sebastijan, "Design and implementation of location service based on signal strength difference", IEEE 13th International Conference on Intelligent Environments, 2017, p. 1-5

[4] M. C. Megasakti, "Design Autotracking with Microcontroller, GPS, Sat Finder and Digital Compass for Azimuth's Antennas Sinchronization to Satelit Cakrawalata-2 Satelitte", Departement of Electrical Engineering Universitas Indonesia, 2010

[5] M. M. Awaludin, "Design and Implementation Automatic Finder for Antennas Directivity based GPS Modul microcontroller ATMEGA 8535", Departement of Telecommunication Engineering Universitas Telkom, Bandung, 2012

[6] S. Aydin and H. Ibrahim, "Antenna Azimuth Position Control with PID, Fuzzy Logic and Sliding Mode Controllers", IEEE International Symposium on Innovation Intellegent System and Applications (INISTA), 2016, p. 10-15

[7] F. Kocadag and A. Demirkol, "Real Tracking of TV Satellites on Moving Vehicles Using Kalman Filter", IEEE 2nd International Conference on Signal Processing and Integrated Network (SPIN), 2015, p. $1-5$

[8] T. Ren and M.G. Potevello, "A Stand Alone Approach for High Sensivity GNSS Receivers in Signal Challenged Evironment", IEEE Transactions on Aerospace and Electronic System, 2017, p. 1-12

[9] K.M. Gayathri, N. Thangadurai and M.P. Vasudha, "Performance Analysis of IRNSS receiver Signal Strength and Accuracy on a Moving Vehicles", IEEE International Conference on Advanced Communication Control and Computing Technologies (ICACCCT), 2016, p. 616-623

[10] Y. Sangesfidi, S. Ziaeinnejad and A.M. Sani, "A New Motor Drive to Control a Two Phase Induction Motor and a DC Motor', IEEE, 2015, p.818-822

[11] K.S.R. Kumar, Jaideep, Rohit and Vikas, "Microprosessor Based Closed Loop Speed Control of DC Motor Using PWM", International Conference on Control, Instrumentation, Communication and Computical Technologies (ICCICCT), 2015, p. $255-257$

[12] M.D. Marcu, R.I. Slusariuc, F.G. Popescu, and L.B. Samolia, "Universal DC Motor Protection System Based on Microcontroller
Embedded Algoritm", International Symposium on Fundamental of Electrical Engineering University Plitechnica of Bucharest, Romania, November 2018, p. 1-3

[13] A. Albasir, K. Naik and T. Abdunabi, "Smart Mobile Web Browsing", IEEE, 2016, p. 671-678

[14] J. Lim, S. Lee, G. Tewolde and J. Kwon, "Indoor Localization and Navigation for a Mobile Robot Equippped with Rotating Ultrasonic Sensors using a Smartphone as the Robot's Brain", IEEE, 2015, p. 621-625

[15] M. Roy, and S. Oh, "Smartphone Based Automated Microparticle Analysis System", IEEE, 2015, p. 1-3

[16] P. Pratumsuan and K. Chanaisawan, "Applying the Smartphone on Position Tracking Control of Servo Pneumatic Systems", IEEE, 2016, p. 1-5

[17] T. Nishimura, Y. Yoshimura, et.al, "Azimuth Characteristic of Radio Wave Propagation in a Mulberry Farm in 920-MHz Band," IEEE, 2017, p. 182-184

[18] J. Li and D, Jiang, "Joint Elevation and Azimuth Angles Estimation for L-Shaped Array", IEEE Antennas and Wireless Propagation Letters, 2016, p. 1-4

[19] H. Chen, C. Hou, et.al, "Improved Azimuth/Elevation Angle Estimation Algoritm for Three-Parallel Uniform Linear Arrays, IEEE Antennas and Wireless Propagation Letters, Vol. 14, 2015, p. 329-332

[20] F. Keskin, and T. Filik, "3D-Shaped Array Design for Full Isotropic Azimuth and Elevation Angle Estimation”, IEEE, 2019, p. 1-4

[21] O.D. Ayansola and A. Henry E.C.A, "Mathematical Modelling of Antenna Look Angles of Geostationary Communications Satellite Using Two Models of Control Stations," IEEE 3rd International Conference on Advanced Computer Theory and Engineering (ICACTE), 2010, p. 236-240

[22] H. Cho, S.C. Chae, at.al, "Azimuth Pattern Reconfigurable Magnetic Dipole Antenna with Wide Angle Coverage," Proceeding of the 49th European Microwave Conference, 2019, p. 1052-1055

[23] K. Kitao, T. Imai, K. Saito and Y. Okumura," Elevation Directional Channel Properties at BS to Evaluate 3D Beamforming", IEEE, 2013, p. 640-644

[24] K. Yu, C. Rizos and A.G. Dempster, "Forest Change Detection Based On GNSS Signal Strength Measurements," IEEE, 2013, p. 1003-1006

[25] J. Norris, B. Taylor and W. Tyler, "Methods of Detection of Bandlimited Signals on UHF MILSATCOM Downlink", IEEE Military Communications Conference, 2013, p. 1819-1824

[26] Z. Shen, J. Li, and Q. Wu, "Data-Driven Interference Localization Using a Single Satellite Based on Received Signal Strength", IEEE Transaction on Vehicular Technology, 2020, p. 1-15

[27] J. Miao, P. Wang, et.al, "AMulti-attribute Decision Handover Scheme for LEO Mobile Satellite Networks", IEEE 5th International Conference on Computer and Communications, 2019, p. $938-942$

[28] Raghu, R. Kumar M, and Shubhanka, "Tracking and Analysis of IRNSS and GPS Satellites by Using Satellite Tool Kit", IEEE International Conference on Recent Trnds in Electronics, Informatic \&Communication Technology, May 18 th, 2018, p. 126-130

[29] M. Nugroho and N.M.N. Khamsah, "Study of Impact of Outdated Two-Line Element Sets in Tracking of LAPAN-A2 and LAPAN-A3 Satellites", IEEE International Conference on Aerospace Elecronics and Remote Sensing Technology, 2018, p. 1-6

[30] Raghu, Manjunatha, and Kiran, "Determination and Preliminary Analysis of Position Accuracy on IRNSS Satellites", IEEE International Conference on Communication and Signal Proceeding, April 6th-8th, 2016, p. 765-769

[31] M. Aorpimai, V. Malayvej and P. Navakitkanok, "High Fidelity Orbit Propagator for Precise Antenna Pointing in LEO Satellite Operation", IEEE, 2014, p. 223-226 